\title{
Potential habitat corridors and restoration areas for the black-and-white snub-nosed monkey Rhinopithecus bieti in Yunnan, China
}

\author{
Li Li, Yadong Xue, Gongsheng Wu, Diqiang Li and Patrick Giraudoux
}

\begin{abstract}
The black-and-white snub-nosed monkey Rhinopithecus bieti is endemic to China, where its population is fragmented into 15 isolated groups and threatened despite efforts to protect the species. Here we analyse possible habitat connectivity between the groups reported in Yunnan, using genetic, least-cost path and Euclidean distances. We detect genetic isolation between the northern and southern groups but not among the northern groups. We show that genetic distance is better explained by human disturbance and land-cover least-cost paths than by Euclidian distance. High-quality habitats were found to be more fragmented in the southern part of the study area and interspersed with human-influenced areas unsuitable for black-andwhite snub-nosed monkeys, which may explain the genetic isolation of the southern groups. Potential corridors are identified based on the least-cost path analysis, and seven sensitive areas are proposed for restoration. We recommend (1) that restoration is focused on the current range of the monkeys, with efforts to reduce human disturbance and human population pressure and increase public awareness, and (2) the development of a long-term plan for habitat restoration and corridor design in the areas between groups.
\end{abstract}

Keywords Black-and-white snub-nosed monkey, China, corridor, habitat, least-cost path, Rhinopithecus bieti, simulation

\section{Introduction}

$T$ he black-and-white snub-nosed monkey Rhinopithecus 1 bieti is endemic to Yunnan, China, and categorized as Endangered on the IUCN Red List (Bleisch \& Richardson, 2008). Surveys have shown that the monkeys live in 15 isolated groups, with a total of c. 2,500 individuals (Jin \& Long,

Li LI (Corresponding author) and GoNGSHENG WU Department of Wildlife Management and Ecosystem Health, Yunnan University of Finance and Economics, 237\# Long Quan Road, Kunming, Yunnan, 650221, People's Republic of China. E-mail lilyzsu@gmail.com

YADONG XUE and DiQIANG Li Key Laboratory of Forest Ecology and Environment, State Forestry Administration of Institute of Forest Ecology, Chinese Academy of Forestry, Beijing, People's Republic of China

Patrick Giraudoux Chrono-environnement department UFC/CNRS Université de Franche-Comté and Institut Universitaire de France, Besançon, France

Received 15 February 2013. Revision requested 29 April 2013

Accepted 1 October 2013. First published online 3 July 2014.
2010), in a narrow range from Mangkang in Tibet to Yunlong in the Yunling Mountains, in Yunnan Province, at 1,800-4,513 m altitude (Long et al., 1994, 1996). Groups are scattered in the Three Parallel Rivers region, one of the most ecologically important areas in China, the rugged terrain of which makes it difficult to carry out surveys. Circa $80 \%$ of the species' global population is distributed in the north-west region of Yunnan and the remainder is in southeast Tibet. The species is threatened by habitat alteration (Zhao, 1988; Zhao et al., 1988), poaching (Bai, 1987) and economic activities such as farming and collection of timber (Xiang et al., 2007a), and the areas between populations are damaged by logging, grazing, mining, agriculture and the livelihood activities of local people, including firewood collection. Because of this habitat fragmentation the monkeys may incur a high energy cost if they travel long distances between habitat patches (Kirkpatrick, 1996; Ren et al., 2009). Fragmentation may also prevent genetic exchange between populations, making the species more vulnerable to extinction (Xiao et al., 2003; Li et al., 2008; Li et al., 2009a,b; Liu et al., 2009; Grueter et al., 2012).

Based on genetic analysis $R$. bieti populations have been grouped into five management units $\left(\mathrm{S}_{1}-\mathrm{S}_{5}\right)$ for conservation (Liu et al., 2007, 2009). S1 is in the north-west of the range, confined within an isolated patch of forest and separated from the other management units by National Road 214 and a strip of human settlements. National Road 214 also separates $S_{1}$ and $S_{2}$ from the other management units. To the south-east, $S_{4}$ and $S_{5}$ are surrounded by cultivated land and towns (Fig. 1).

Where required, reserve managers need to establish habitat corridors to facilitate genetic exchange between populations, identifying priority areas for restoration to increase landscape connectivity.

Here we address the issue of how habitat corridors linking isolated groups of $R$. bieti can be designed effectively. We compare Euclidean distance and landcover weighted, human-disturbance weighted cost distances between groups, and on this basis we propose priority areas for habitat restoration and make recommendations for managers.

\section{Study area}

R. bieti populations are localized in ridge-top patches of primary forest along the $300 \mathrm{~km}$ spine of the Yunling 


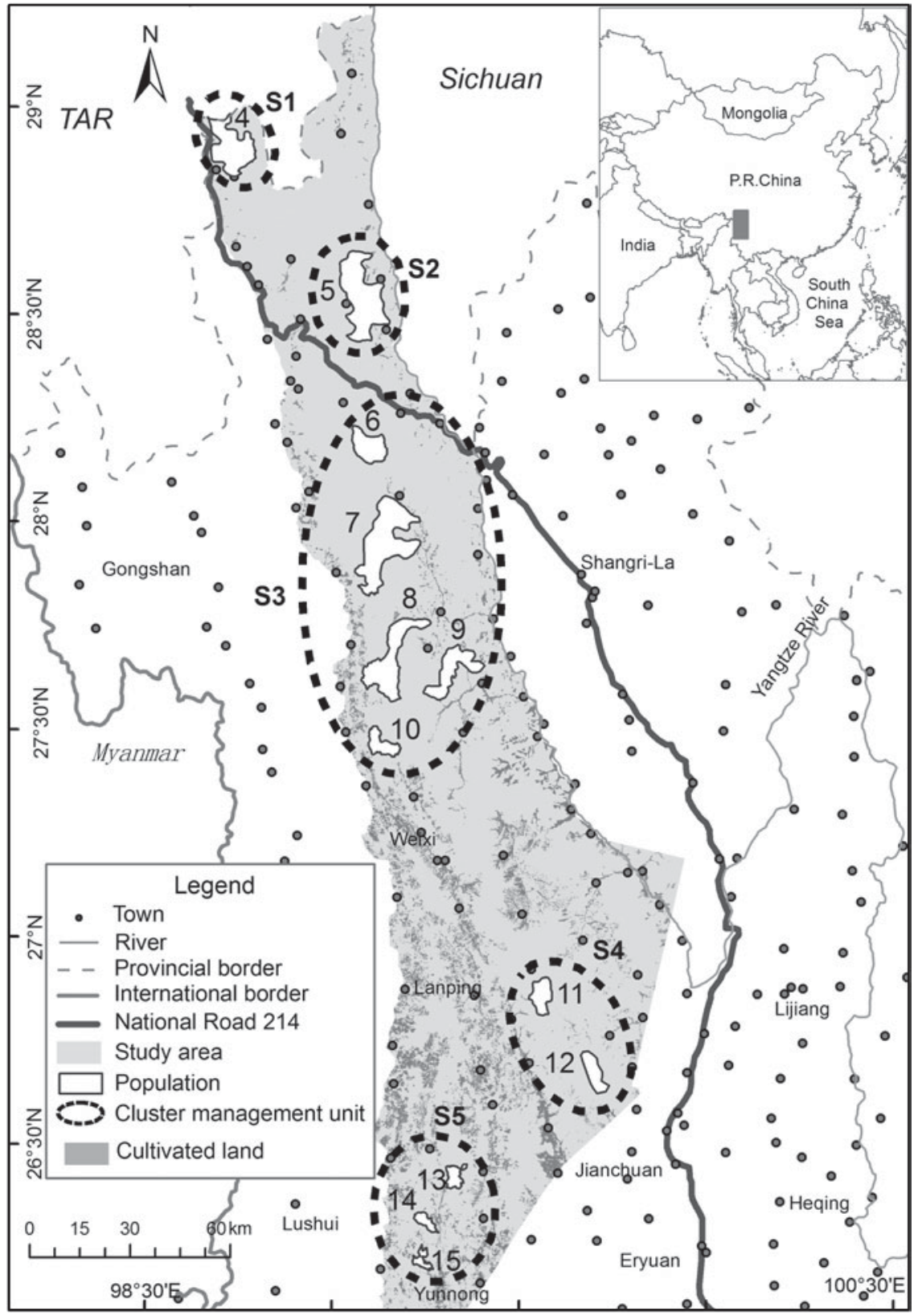

FIG. 1 Distribution of the black-andwhite snub-nosed monkey Rhinopithecus bieti in Yunnan, China. The rectangle on the inset indicates the location of the main map in China.
Mountains (Fig. 1). Given the lack of data from the Tibet Autonomous Region (groups $\mathrm{G}_{1}-\mathrm{G}_{3}$ ), this study is limited to populations within Yunnan Province and is based on previous genetic studies that identified 12 discrete groups in Yunnan (G4-G15; Liu et al., 2007, 2009).

Ecological conditions vary from north to south within the species' distribution range. Towards the south the mountains decrease in elevation, and temperature, precipitation and biodiversity increase. The northern group of monkeys forages in dark coniferous forest dominated by fir, and the diet of this group consists primarily of lichens (Kirkpatrick et al., 1998). The middle and southern groups forage primarily in mixed coniferous and broadleaf forest and their diet is more diverse. Habitats at lower elevations tend to be complex in terms of plant species composition and usually contain more diverse food items than habitats at higher elevations. From north to south, R. bieti show a tendency to feed on more plant species and to consume more non-lichen foods (Xiang et al., 2007b). Overall, forest vegetation in this region can be categorized as follows, ranked in descending order of elevation: (1) dark-coniferous forest (Abies georgei), (2) mixed coniferous and broadleaf forest, and (3) Yunnan pine Pinus yunnanensis forest. Only (1) and (2) are known to be suitable habitats for $R$. bieti (Kirkpatrick et al., 1998; Xiao et al., 2003; Li et al., 2008).

\section{Methods}

The analysis was based on a classified vegetation map $(2.5 \times 2.5 \mathrm{~km}$ resolution $)$ derived from an assemblage of 
13 SPOT5 satellite images (November 2004, 60 ×60 km) covering the study area, with ground-truthing carried out by the Conservation Information Centre of The Nature Conservancy's China programme.

The genetic distances between pairs of monkey populations were obtained from Liu et al. (2007, 2009), in which two blood, two muscle and 203 faecal samples from eight groups $\left(\mathrm{G}_{4}, 5,6,9,10,11,13,15\right)$ across our study area were assessed by sequencing across $401 \mathrm{bp}$ of the hypervariable I segment of the mitochondrial DNA of 157 individuals. In total, 52 variable sites were found and 30 haplotypes defined (Liu et al., 2007). We performed a hierarchical cluster analysis on the genetic distance matrix, using Rousset's distance measure FST/(1-FST) to visualize genetic proximity between all groups. The analysis was based on Ward's method, implemented in $R$ v. 2.14.1 (Ward, 1963; R Development Core Team, 2012).

We performed a least-cost path analysis to identify potential dispersal corridors and determine the cost of movement. This approach calculates between-patch distances, based on assignment of relative resistance to dispersal for each cover type in the landscape. A routing Djikstra algorithm then finds the least costly path from a donor patch to a target patch, and the cost of this path is taken as the distance between the two patches. According to the vegetation map there are five land-cover categories: optimal suitable habitat (dark coniferous forest), suboptimal habitat (mixed coniferous and broadleaf forest), shrubs, meadows and cultivated land.

We extracted four human-disturbance factors (road density, distance to road, human population density and distance to town) from 1:250,000 topographical maps from the China Mapping Centre. Most variables related to human disturbance are correlated, and therefore we used a principal component analysis in ArcGIS v. 9.3 (ESRI, Redlands, USA) to compute new variables, each of which was a linear combination of the original variables and orthogonal to (independent of) the others. Axis 1, bearing the largest possible variance, was divided into five classes of equal intervals, representing a gradient of human disturbance.

To infer the appropriate costs for each land-cover type and human-disturbance index class we calculated leastcost distance over a range of values and compared them to the genetic distance by (1) assigning hypothetical costs to each land-cover type or human disturbance, (2) calculating the least-cost distances between groups, based on these costs, and (3) determining the best assignments for habitat viscosity or human disturbance by comparing the correlation between the least-cost path distance for the hypothetical costs and the genetic distance matrices. The relationship between the genetic distance as response variable and the other distances (Euclidian, least cost, land cover, human disturbance) was modelled using a multiple regression of distance matrices (Lichstein, 2007). A permutation test $(R=9,999)$ was used to test the null hypothesis of no correlation among genetic and least-cost path distance, and computing was carried out using R v. 2.14.1 and Ecodist v. 1.4-7 (Goslee \& Urban, 2007).

The most suitable habitat and the minimum human disturbance (class 1) were assigned a resistance value of 1 ; the most unsuitable habitat (cultivated land) and the maximum human disturbance (class 5) were assigned a resistance value of 100 (Chardon et al., 2003; Wu et al., 2009). These were considered fixed values. For classes 2,3 and 4 the resistance values were explored in increments of 10 to maximize $R^{2}$ of the multiple regression of distance matrices with land cover and human disturbance separately. This resulted in a total of 84 least-cost path analyses based on different combinations. Computing was performed using ArcView and the add-on PATHMATRIX (Ray, 2005). We compared univariate and multivariate models (e.g. with land cover and human disturbance as independent variables) to select the best model for explaining genetic distances.

We used the optimal costs to compute least-cost paths and define potential corridors on this basis, considering both human disturbance and land-cover viscosity values. For each pixel of the map, the larger of these two values was assigned.

Based on our field experience we set three conditions for the choice of areas suitable for restoration of the blackand-white snub-nosed monkey: they should be sensitive areas and possible stepping-stones, and they should be located in a nature reserve, for ease of restoration. Sensitive areas are patches where current or future human activities are expected to cause significant damage to the ecosystem (Epps et al., 2007; Holderegger \& Wagner, 2008; Wang et al., 2009; Wu et al., 2009, 2010; Xue et al., 2011), and stepping-stones are patches of favourable habitat that facilitate dispersal among fragmented populations (Saunders, 2007).

National Road 214 is a permanent habitat barrier, and therefore we focused on habitat restoration for groups G6-G15. We superimposed National Roads, cultivated vegetation, and towns on a map to identify gaps between favourable habitats and propose possible restoration areas.

\section{Results}

Our cluster analysis revealed three primary genetic groups (Fig. 2): (1) G13 and G15, (2) G10, G11 and G5, and (3) G4, G6, G7 and G9.

Univariate analyses showed that genetic distance was better explained by human disturbance and land-cover 
TABLE 1 Results of regression models with and without G11. The genetic distance is the response variable and the other distances are the independent variables (see Methods).

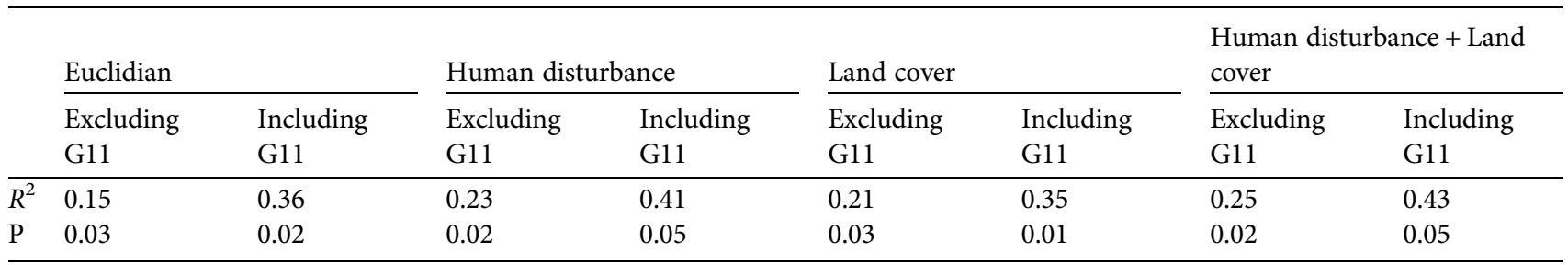

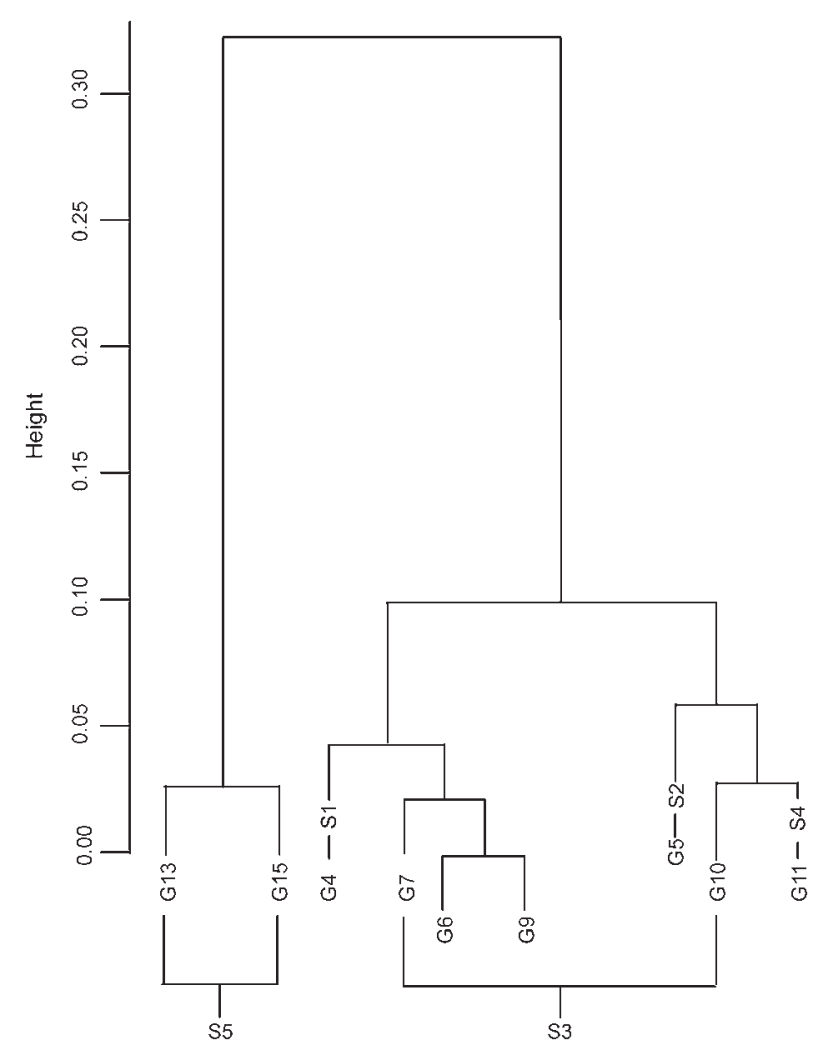

FIG. 2 Cluster dendrogram of the genetic distances, based on Ward's method.

least-cost paths than by Euclidian distance (Table 1). Multivariate models combining land cover and human disturbance did not perform much better than univariate models, indicating a strong covariation between land cover and human disturbance. In all cases the inclusion of G11 in the analysis of the northern groups yielded a large increase in $R^{2}$, indicating that isolation by distance $\left(R^{2}=0.15\right)$ was greater for this group. No isolation by distance $\left(R^{2}=0.36\right)$ was found if the southern groups $\mathrm{G}_{11}$ and $\mathrm{G}_{13}-\mathrm{G}_{15}$ were excluded.

Fig. 3 shows the corridors obtained from the least-cost path analysis. The highest correlation between genetic and least-cost path distances $(R=0.25, \mathrm{P}=0.02)$ was obtained with cost assignments of 1, 10, 50, 60, 70, 80 and 100, based on combining human disturbance and land-cover type (Table 2).
Figs 1 and 3 show that high-quality habitats are fragmented in the southern part of the study area and are interspersed with human-influenced areas unsuitable for black-and-white snub-nosed monkeys. In this context we propose seven sensitive areas for restoration (e.g. reforestation, reinforced protection of the forest and the monkeys). Figs 1 and 3 also show the status of human disturbance at the study site.

Table 3 shows the pairwise dispersal cost between monkey populations and indicates that genetic groups G6-G10 have high connectivity with the other groups because the corridors lie in the range of suitable habitat. The areas between the southern groups (G8, G9 and G10) contain more artificial barriers than those between the northern groups (G6 and $\mathrm{G} 7$ ), indicating potentially higher connectivity among the northern groups. The groups G11 and G12 (management unit $\mathrm{S}_{4}$ ) have medium connectivity. Parts of the corridor cross suitable habitats, whereas other parts lie in non-suitable habitat, reducing the connectivity. The groups G14 and G15 (management unit $\mathrm{S}_{5}$ ) have the lowest connectivity because potential corridors lie primarily in cultivated vegetation.

\section{Discussion}

Our results show a north-south gradient of genetic isolation by distance if the southern groups $\mathrm{G}_{13}-\mathrm{G}_{15}$ and/or G11 are included in the analysis, and also indicate that the southernmost groups are the most genetically differentiated. This may be explained by a longer history of isolation or smaller population sizes, both of which imply a threat to the survival of these groups (Hanski et al., 1995; Paetkau et al., 1995). Both hypotheses are consistent with the observation that favourable habitats are smaller and more fragmented in this area (Fig. 3).

In contrast, groups $\mathrm{G}_{4}-\mathrm{G} 11$ appear to be more genetically homogenous (Fig. 2) and are still connected by forest corridors, visible both on maps and in the field, which may serve as links between patches, although the inclusion of G11 in the analysis yields significant genetic isolation by distance. Group 11 may have been isolated more recently (genetically it is closer to the groups of management unit $\mathrm{S}_{3}$ ) and this could also result from smaller 


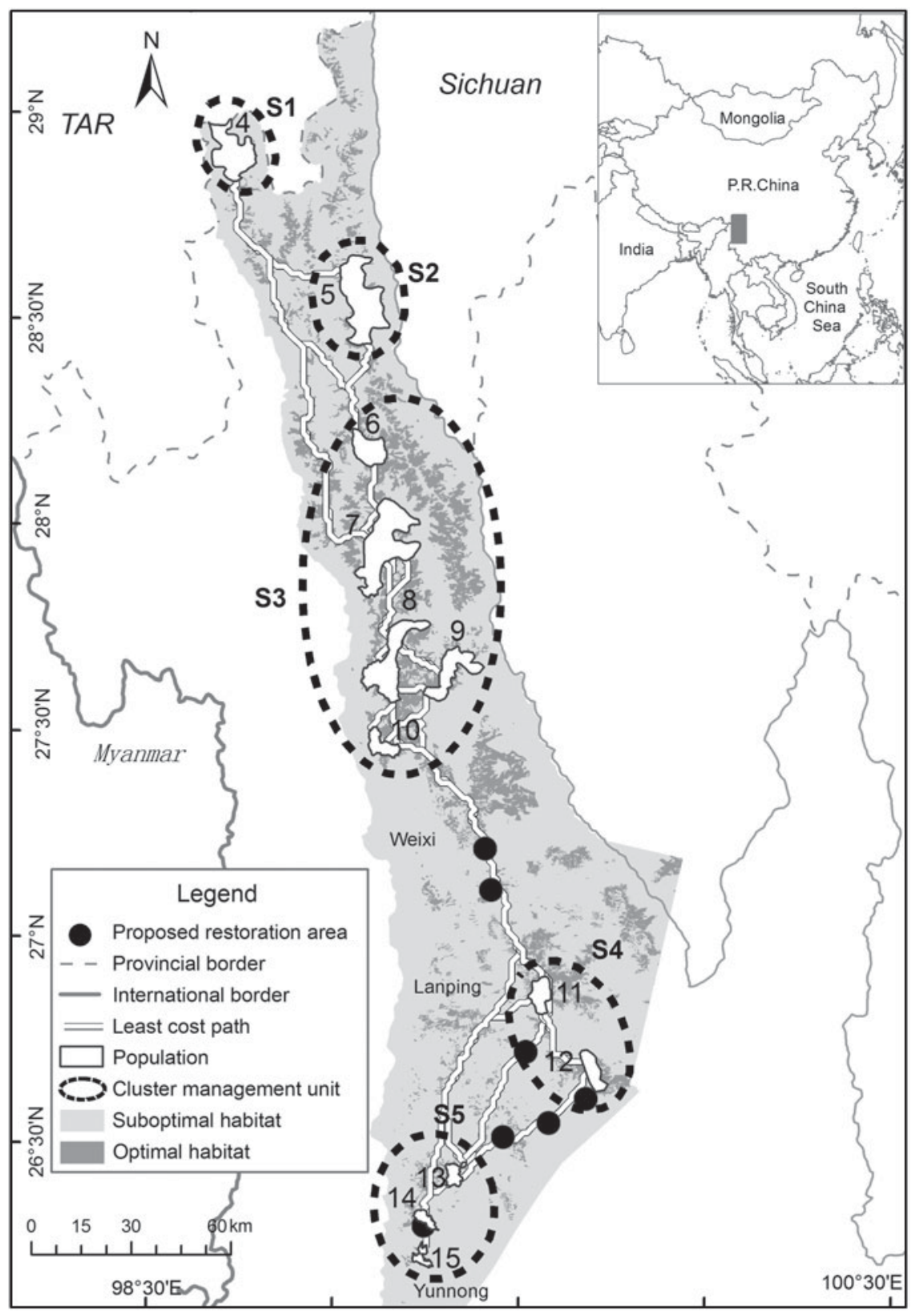

FIG. 3 Least-cost path between populations of the black-and-white snub-nosed monkey in Yunnan, China (Fig. 1), showing the location of optimal and suboptimal habitat and proposed restoration areas.

population sizes, which would increase the level of drift and thus genetic distance. Groups 4 and 5 have been isolated from other groups even more recently by National Road 214.

The potential corridors between $\mathrm{S}_{3}$ and $\mathrm{S}_{4}$ and within $\mathrm{S}_{5}$ would be the most difficult areas to restore because human populations and infrastructure are concentrated in the southern part of the study area, around $\mathrm{S}_{4}$ and $\mathrm{S}_{5}$. These areas coincide with where the least-cost path is blocked by urbanization and the expansion of farmland; however, they represent key areas for restoration, conditional on reducing human disturbance (Dong, 2009). Based on our analyses we propose seven areas for restoration, primarily located between $\mathrm{S}_{3}, \mathrm{~S}_{4}$ and $\mathrm{S}_{5}$ (Fig. 3). These could be managed by the Baimang Snow Mountain Nature Reserve in Weixi,
TABLE 2 Cost assignments for human-disturbance index classes and land-cover types.

\begin{tabular}{lr}
\hline & Cost \\
\hline Human disturbance index class & 1 \\
1 & 10 \\
2 & 70 \\
3 & 80 \\
4 & 100 \\
5 & \\
Land-cover type & 1 \\
Optimal suitable habitat & 50 \\
Suboptimal suitable habitat & 60 \\
Shrubs & 70 \\
Meadows & 100 \\
Cultivated land &
\end{tabular}


TABLE 3 Pairwise dispersal cost (×1000) between groups (G4-G15) of black-and-white snub-nosed monkeys Rhinopithecus bieti.

\begin{tabular}{|c|c|c|c|c|c|c|c|c|c|c|c|c|}
\hline Group & G4 & G5 & G6 & G7 & G8 & G9 & G10 & G11 & G12 & G13 & G14 & G15 \\
\hline G4 & 0.00 & & & & & & & & & & & \\
\hline G5 & $1,610.74$ & 0.00 & & & & & & & & & & \\
\hline G6 & $2,396.31$ & 476.40 & 0.00 & & & & & & & & & \\
\hline G7 & $6,052.60$ & 513.44 & 25.97 & 0.00 & & & & & & & & \\
\hline G8 & $2,462.46$ & 641.75 & 154.28 & 75.01 & 0.00 & & & & & & & \\
\hline G9 & $2,688.29$ & 867.59 & 38.01 & 300.85 & 166.56 & 0.00 & & & & & & \\
\hline G10 & $2,852.45$ & $1,031.75$ & 544.28 & 465.01 & 187.27 & 342.13 & 0.00 & & & & & \\
\hline G11 & $5,286.90$ & $3,466.20$ & $2,978.31$ & $2,899.46$ & $2,621.72$ & $2,684.15$ & $2,448.58$ & 0.00 & & & & \\
\hline G12 & $6,084.89$ & $4,264.19$ & $3,776.72$ & $3,697.45$ & $3,419.71$ & $3,482.14$ & $3,246.58$ & 702.27 & 0.00 & & & \\
\hline G13 & $7,867.61$ & $6,046.92$ & $5,559.45$ & $5,480.17$ & $5,202.44$ & $5,264.87$ & $5,029.31$ & $2,487.85$ & $2,021.07$ & 0.00 & & \\
\hline G14 & $8,440.04$ & $6,619.34$ & $6,131.87$ & $6,052.60$ & $5,774.87$ & $5,837.29$ & $5,601.74$ & $3,073.44$ & $2,671.91$ & 475.26 & 0.00 & \\
\hline G15 & $8,963.47$ & $7,142.78$ & $6,655.31$ & $6,576.03$ & $6,299.30$ & $6,360.73$ & $6,125.16$ & $3,569.87$ & $3,195.34$ & 998.70 & 319.49 & 0.00 \\
\hline
\end{tabular}

Lanping and Lijiang Counties, with the help of local authorities.

Our approach primarily identifies landscape features that strongly correlate with gene flow (Balkenhol \& Landguth, 2011; Jaquiery et al., 2011). We expect this to be the case with the land-cover and human-disturbance features evaluated here; however, we still know little about the ecology and behaviour of the black-and-white snubnosed monkey.

Least-cost modelling is commonly employed to assign dispersal costs to distinct habitat types and to calculate the least costly dispersal paths among habitat patches (Epps et al., 2007). The emerging field of landscape genetics uses high-resolution genetic data to determine the influence of landscape features such as fields (Vos et al., 2001) or highways (Epps et al., 2003; Keller \& Largiader, 2003) on gene flow and dispersal (Manel et al., 2003). However, power and accuracy are often questionable when relevant data on dispersal are lacking and landscape complexity increases (Balkenhol \& Landguth, 2011; Jaquiery et al., 2011). Our approach has, therefore, a number of limitations; for example, we simplified landscape types, categorizing them for ease of modelling. This results in an over-simplification, especially regarding vegetation conditions. A second limitation is that the anthropogenic barriers may vary (e.g. tunnels are built that may decrease mountain road traffic), and subsequently new corridors may appear in places where the species is no longer present. We dealt with this by taking into account four disturbance factors (road density, distance to road, population density and distance to town), using a principal component analysis, but until re-created corridors are used by monkeys there will always be uncertainty regarding their suitability.

The extent to which our method and results are applicable to conservation management will depend on the local landscape and the repeatability of our results across the range of the species. Direct field observations and measurements are necessary to understand the detailed effects of different habitats on dispersal; it is possible that spatial differences at a finer scale, such as subtle terrain contours in mountainous areas, contribute to the cost of traversing a landscape. With increasingly detailed spatial data these fine-scale patterns could be resolved. However, within these limitations our study is a first step towards better design of areas for restoration.

Based on our results we recommend (1) that restoration efforts focus on the current range of the monkeys, with efforts to reduce human disturbance and human population pressure and increase public awareness, and (2) the development of a long-term plan for habitat restoration and corridor design in the areas between groups, based on site-specific conditions, and regional development compatible with the protection of the species. For instance, livestock enclosures and techniques that increase agricultural efficiency could be introduced to reduce pressure on the forests that the snub-nosed monkey depends on, and measures could be taken to encourage use of fuels other than firewood. Promoting techniques that increase agricultural efficiency could help reduce the encroachment of agriculture on forests. We will convey our findings to the public and the relevant authorities, and we intend to have our recommendations integrated into the Yunnan Biodiversity Conservation Action Plan.

\section{Acknowledgements}

This study was supported by the National Natural Science Foundation of China (NSFC no. 31100351). We thank Dr Zhijing Liu for contributing genetic research, and Mrs Sara Gavryck and Mrs Yongmei Luo of The Nature Conservancy's China Programme, for their valuable suggestions on data integration and processing. This research has been conducted within the context of the GDRI (International Research Network) Ecosystem Health and Environmental Disease Ecology. 


\section{References}

B AI, S.C. (1987) Survey on hunting of Yunnan golden monkeys. China Wildlife, 13, 14-15. [In Chinese]

Balkenhol, N.\& Landguth, E.L. (2011) Simulation modeling in landscape genetics: on the need to go further. Molecular Ecology, 20, 667-670.

Bleisch, W. \& Richardson, M. (2008) Rhinopithecus bieti. In IUCN Red List of Threatened Species v. 2013.2. Http://www.iucnredlist.org [accessed 3 March 2014].

Chardon, J.P., Adriaensen, F. \& Matthysen, E. (2003) Incorporating landscape elements into a connectivity measure: a case study for the speckled wood butterfly (Pararge aegeria L). Landscape Ecology, 18, 561-573.

DoNG, Q. (2009) Linear manmade structures, landscape fragmentation, and ecological consequences. In Lectures in Modern Ecology (IV): Theory and Applications, pp. 270-286. Higher Education Press, Beijing, China.

Epps, C.W., Bleich, V.C., Wehausen, J.D. \& Torres, S.G. (2003) Status of bighorn sheep in California. Desert Bighorn Council Transactions, 47, 20-35.

Epps, C.W., Wehausen, J.D., Bleich, V.C., Torres, S.G. \& Brashares, J.S. (2007) Optimizing dispersal and corridor models using landscape genetics. Journal of Applied Ecology, 44, 714-724.

Goslee, S.C. \& Urban, D.L. (2007) The ecodist package for dissimilarity-based analysis of ecological data. Journal of Statistical Software, 22, 1-19.

Grueter, C.C., Li, D., Ren, B., Xiang, Z. \& Li, M. (2012) Food abundance is the main determinant of high-altitude range use in snub-nosed monkeys. International Journal of Zoology. Http://dx.doi.org/10.1155/2012/739419 [accessed 4 March 2014].

Hanski, I., Pakkala, T., Kuussaari, M. \& Lei, G. (1995) Metapopulation persistence of an endangered butterfly in a fragmented landscape. Oikos, 72, 21-28.

Holderegger, R. \& Wagner, H.H. (2008) Landscape genetics. BioScience, 58, 199-207.

Jaquiery, J., Broquet, T., Hirzel, A.H., Yearsley, J. \& Perrin, N. (2011) Inferring landscape effects on dispersal from genetic distances: how far can we go? Molecular Ecology, 20, 692-705.

Jin, T. \& LonG, Y.C. (2010) Anti-poaching, the most effective strategy in saving China's wildlife: lessons learnt from Yunnan snub-nosed monkey initiative. Primate Research, 26(Suppl.), 26.

Keller, I. \& Largiader, C.R. (2003) Recent habitat fragmentation caused by major roads leads to reduction of gene flow and loss of genetic variability in ground beetles. Proceedings of the Royal Society of London, Series B, 270, 417-423.

Kirkpatrick, R.C. (1996) Ecology and behavior of the Yunnan snub-nosed langur Rhinopithecus bieti (Colobinae). $\mathrm{PhD}$ thesis. University of California, Davis, USA.

Kirkpatrick, R.C., Long, Y.C., Zhong, T. \& Xiao, L. (1998) Social organization and range use in the Yunnan snub-nosed monkey Rhinopithecus bieti. International Journal of Primatology, 19, 13-51.

Li, D., Grueter, C.C., Ren, B., Long, Y., Li, M., Peng, Z. \& Wei, F. (2008) Ranging of Rhinopithecus bieti in the Samage Forest, China. II. Use of land cover types and altitudes. International Journal of Primatology, 29, 1147-1173.

Li, L., Yu, S., ReN, B., Li, M., Wu, R. \& LonG, Y. (2009a) A study on the carrying capacity of the available habitat for the Rhinopithecus bieti population at Mt Laojun in Yunnan, China. Environmental Science and Pollution Research International, 16, 474-478.

Li, L., YU, S., Ren, B.P., XIE, G.Q., HuAn G, Z.Y. \& Long, Y.C. (2009b) Simulated spatial distribution of the Yunnan snub-nosed monkey's potential habitat using SOPT5 image in Laojun Mountain Area. Wildlife Biology in Practice, 5, 59-69.
Lichstein, J.W. (2007) Multiple regression on distance matrices: a multivariate spatial analysis tool. Plant Ecology, 188, 117-131.

LiU, Z., Ren, B., Wei, F., Long, Y., HaO, Y. \& Li, M. (2007) Phylogeography and population structure of the Yunnan snub-nosed monkey (Rhinopithecus bieti) inferred from mitochondrial control region DNA sequence analysis. Molecular Ecology, 16, 3334-3349.

LiU, Z., Ren, B., Wu, R., Zhao, L., Hao, Y., Wang, B. et al. (2009) The effect of landscape features on population genetic structure in Yunnan snub-nosed monkeys (Rhinopithecus bieti) implies an anthropogenic genetic discontinuity. Molecular Ecology, $18,3831-3846$.

LonG, Y., Kirkpatrick, C.R., Zhong, T. \& Xiao, L. (1994) Report on the distribution, population, and ecology of the Yunnan snub-nosed monkey (Rhinopithecus bieti). Primates, 35, 241-250.

Long, Y., Kirkpatrick, C.R., Zhong, T. \& Xiao, L. (1996) Status and conservation strategy of the Yunnan snub-nosed monkey. Chinese Biodiversity, 4, 145-152.

Manel, S., Schwartz, M.K., Luikart, G. \& Taberlet, P. (2003) Landscape genetics: combining landscape ecology and population genetics. Trends in Ecology and Evolution, 18, 189-197.

Paetikau, D., Calvert, W., Stirling, I. \& Strobeck, C. (1995) Microsatellite analysis of population structure in Canadian polar bears. Molecular Ecology, 4, 347-354.

R Development Core Team (2012) R: A Language and Environment for Statistical Computing. R Foundation for Statistical Computing, Vienna, Austria.

RAY, N. (2005) PATHMATRIX: a GIS tool to compute effective distances among samples. Molecular Ecology Notes, 5, 177-180.

Ren, B., Li, M., Long, Y., Wu, R. \& Wei, F. (2009) Home range and seasonality of Yunnan snub-nosed monkeys. Integrative Zoology, $4,162-171$.

Saunders, D.A. (2007) Connectivity, corridors and stepping stones. In Managing and Designing Landscapes for Conservation: Moving from Perspectives to Principles (eds D.B. Lindenmayer \& R.J. Hobbs), pp. 280-289. Blackwell Publishing Ltd, Oxford, UK.

Vos, C.C., Antonisse-De Jong, A.C., Goedhart, P.W. \& SMUlders, M.J. (2001) Genetic similarity as a measure for connectivity between fragmented populations of the moor frog (Rana arvalis). Heredity, 86, 569-608.

Wang, I.J., Savage, W.K. \& Shaffer, H.B. (2009) Landscape genetics and least-cost path analysis reveal unexpected dispersal routes in the California tiger salamander (Ambystoma californiense). Molecular Ecology, 18, 1365-1374.

WARD, JR, J.H. (1963) Hierarchical grouping to optimize an objective function. Journal of the American Statistical Association, $58,236-244$.

Wu, C.G., Zhou, Z.X., Wang, P.C., Xiao, W.F., Teng, M.J. \& PENG, L. (2009) Evaluation of landscape connectivity based on least-cost model. Chinese Journal of Applied Ecology, 20, 2042-2048. [In Chinese]

Wu, C.G., Zhou, Z.X., Wang, P.C., Xiao, W.F., \& Teng, M.J. (2010) The concept and measurement of landscape connectivity and its applications. Acta Ecologica Sinica, 30, 1903-1910. [In Chinese]

Xiang, Z.F., Huo, S., Wang, L., Cui, L.W., Xaio, W., Quan, R.C. \& TAI, Z. (2007a) Distribution, status and conservation of the black-and-white snub-nosed monkey Rhinopithecus bieti in Tibet. Oryx, 41, 525-531.

Xiang, Z.F., Huo, S., Xiao, W., Quan, R.C. \& Grueter, C.C. (2007b) Diet and feeding behavior of Rhinopithecus bieti at Xiaochangdu, Tibet: adaptations to a marginal environment. American Journal of Primatology, 69, 1141-1158. 
Xiao, W., Ding, W., Cui, L.W., Zhou, R.L. \& Zhao, Q.K. (2003) Habitat degradation of Rhinopithecus bieti in Yunnan, China. International Journal of Primatology, 24, 389-398.

Xue, Y.D., LI, L., LI, D.Q., Wu, G.S., Zhou, Y. \& Lv, X.X. (2011) Analysis of habitat connectivity of the Yunnan snub-nosed monkeys (Rhinopithecus bieti) using landscape genetics. Acta Ecological Sinica, 31, 5886-5893. (in Chinese).

Zhaо, Q.K. (1988) Status of the Yunnan snub-nosed monkey. Primate Conservation, 9, 131-134.

Zhaо, Q., He, S., Wu, B. \& NAsh, L.T. (1988) Excrement distribution and habitat use in Rhinopithecus bieti in winter. American Journal of Primatology, 16, 275-284

\section{Biographical sketches}

Li Li's research focuses on the conservation of the snub-nosed monkey, and approaches using geographical information systems. YADONG XUE has been involved in ecological research on the snubnosed monkey in China since 2007. Gongsheng WU studies the effects of habitat loss and fragmentation on biodiversity. DIQIANG LI's research focus is on biodiversity inventory and monitoring in protected areas, and regional conservation planning. He has worked on the conservation ecology and genetics of the Przewalski's gazelle, the wild camel and the golden monkey. PATRICK Giradoux studies the effects of landscape on the long-term dynamics of wildlife populations and conservation, and infectious disease transmission. He works mainly in Europe and China but also in Africa, Indonesia and Mexico. 